\title{
Cardiovascular magnetic resonance evaluation for left ventricular diastolic function: analysis of time- volume curve
}

\author{
Takashi Tanimoto ${ }^{*}$, Keizo Kimura, Shingo Ota, Tomizo Masuno, Yuichi Ozaki, Kumiko Hirata, Takashi Kubo, \\ Imanishi Toshio, Takashi Akasaka
}

From 15th Annual SCMR Scientific Sessions

Orlando, FL, USA. 2-5 February 2012

\section{Background}

Although cine magnetic resonance imaging (MRI) is considered the gold standard for evaluation of left ventricular (LV) volumes, mass, and systolic function, assessment of diastolic filling is still challenging. The aim of this study was to assess the impact of LV mass on diastolic function by time-volume curve obtained from cine MRI in patients with dilated cardiomyopathy (DCM) or hypertrophic cardiomyopathy (HCM) and normal subjects.

\section{Methods}

Cine MRI was performed in 10 healthy controls, 11 HCM patients, and 11 DCM patients. LV end-diastolic volume (EDV), end-systolic volume (ESV), stroke volume (SV), ejection fraction (EF), LV mass, and $\mathrm{LVESV} /$ mass ratio were calculated by tracing endocardial and epicardial borders of LV in 8-10 short axis views. Furthermore, to assess the LV diastolic function, the peak filling rate (PFR), time to PFR (TPF), and first third filling fraction $(1 / 3 \mathrm{FF})$ were calculated from the first derivative curve of the time-volume curve. Temporal resolution was 30 frames per R-R interval.

\section{Results}

Resting LVEF were $54 \pm 4 \%$ in Control group, $26 \pm 9 \%$ in DCM group, and $62 \pm 6 \%$ in HCM group. LVSV were similar in 3 groups. LV mass was greater in DCM and HCM group compared to Control group. TPF of HCM groups was longer than both Control and DCM groups. PFR and 1/3FF were greater in Control group compared

\footnotetext{
Cardiovascular Medicine, Wakayama Medical University, Wakayama city,
} Japan

(c) 2012 Tanimoto et al; licensee BioMed Central Ltd. This is an open access article distributed under the terms of the Creative to both DCM and HCM groups. LV mass showed significant inverse relationship with PFR $(r=-0.65$, $\mathrm{p}=0.0001)$ and $1 / 3 \mathrm{FF}(\mathrm{r}=-0.60, \mathrm{p}=0.0002)$.

\section{Conclusions}

LV diastolic parameters can be assessed non-invasively by time-volume curve analysis. LV mass has influence on diastolic filling.

\section{Funding}

None.

Published: 1 February 2012

doi:10.1186/1532-429X-14-S1-P305

Cite this article as: Tanimoto et al:: Cardiovascular magnetic resonance evaluation for left ventricular diastolic function: analysis of time-volume curve. Journal of Cardiovascular Magnetic Resonance 2012 14(Suppl 1):P305.

Submit your next manuscript to BioMed Central and take full advantage of:

- Convenient online submission

- Thorough peer review

- No space constraints or color figure charges

- Immediate publication on acceptance

- Inclusion in PubMed, CAS, Scopus and Google Scholar

- Research which is freely available for redistribution

Submit your manuscript at www.biomedcentral.com/submit 